NBER WORKING PAPER SERIES

\title{
TORTS IN WHICH VICTIM AND INJURER ACT SEQUENTIALLY
}

Steven Shavell

Working Paper No. $\underline{939}$

NATIONAL BUREAU OF ECONOMIC RESEARCH

1050 Massachusetts Avenue

Cambridge MA 02138

July 1982

The research reported here is part of the NBER's research program in Law and Economics. Any opinions expressed are those of the author and not those of the National Bureau of Economic Research. 


\title{
Torts in Which Victim and Injurer \\ Act Sequentially
}

\begin{abstract}
$\underline{\text { ABSTRACT }}$
The effect of liability rules on accident avoidance is studied in two types of situations in which potential victims and potential injurers act sequentially: those where victims act first and injurers second; and those where the reverse is true. What is of special interest about the working of liability rules in such sequential situations is that the party who acts second behaves in response to the party who acts first, and that the party who acts first takes this into account. The major result shown is that liability rules induce optimal behavior provided that they lead the party who acts second to act optimally if and only if the first party did so. In an important extension of the basic model considered, however, this result may not hold.
\end{abstract}

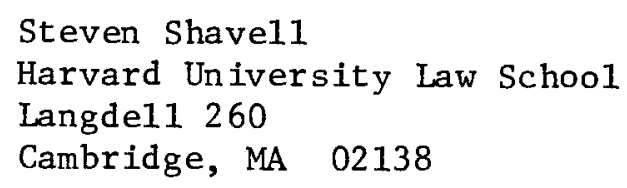


Torts in Which Victim and Injurer Act Sequentially

$$
\text { S. Shavell* }
$$

\section{Introduction}

This article will study the effect of liability rules on accident avoidance in situations where potential victims and potential injurers act sequentially. ${ }^{1}$ Two types of these sequential situations are possible: those where victims act first and injurers ${ }^{2}$ second; and those where the reverse is true. The cases of Davies $\underline{v} \underline{\text { Mann }^{3}}$ and Topping v. Oshawa Railway, ${ }^{4}$ for instance, provide illustrations of both types of situations, as in the former case the victim Davies left his donkey fettered on a road and Mann later came along the road and ran the animal down; while in the latter case a truck halted on streetcar tracks and then the "victim" streetcar traveling down the tracks failed to avoid a collision that resulted in injury to its passengers. Other examples of situations where the victim and the injurer acted sequentially are easily adduced; ${ }^{5,6}$ on reflection, such situations do not seem to be at all infrequent.

In the analysis below of sequential situations, a simple model of accidents will be considered. ${ }^{7}$ In this model, parties are assumed to have full knowledge of accident 
risks and to take the actions that are in their financial self-interest given the applicable liability rule. Four liability rules are studied: the negligence rule with the defense of contributory negligence; this rule without the defense; the comparative negligence rule; and strict liability with a defense of contributory negligence.

What will be of special interest about the working of liability rules in the model is two-fold--that the party who acts second behaves in response to the party who acts first, and that the party who acts first will take the response of the party who acts second into account. 8

This can be illustrated, and the main points of the article indicated, by a brief discussion of Davies. The decision in the case was that despite Davies' contributory negligence in leaving his donkey on the road, he should succeed in his action for negligence against Mann because, in now familiar terms, Mann had the "last clear chance" to prevent harm yet did not try to do so. Use of this doctrine to defeat a defense of contributory negligence is often noted to have two opposing effects on accident avoidance: parties like Mann will be induced to avoid running down fettered animals; ${ }^{9}$ but because parties like Davies would be expected to anticipate such behavior, they will not be properly motivated to fetter their animals safely in the first place. 10 The suggestion, therefore, is that the relative strengths of these two opposing effects will determine 
whether it is desirable to make the defense of contributory negligence unavailable.

In the model, however, availability of the defense of contributory negligence in cases where the victim acts first is generally desirable. To see why, notice that given the availability of the defense, victims like Davies would realize that if they acted in a contributorily negligent way and exposed their animals to risk, injurers like Mann would not fear liability for negligence and would therefore have no motive to avoid running the animals down. In consequence, victims like Davies would find it best to take appropriate care; and given their non-negligent behavior, injurers like Mann would be liable for harm negligently done and would therefore have a motive not to run down such animals as were still exposed to risk. In other words, both victims and injurers would be induced to act appropriately if a defense of contributory negligence were available. (The more general point is that optimal behavior will result under a liability rule provided that it leads the second party to take care if and only if the first party took care.)

Yet it is plain that the argument leading to this conclusion could not necessarily be made if for some reason such as failure to perceive risk certain victims might not take care whatever the liability rule. Specifically, availability of the defense of contributory negligence might then induce certain injurers too not to take care; for whenever 
victims would not take care, injurers would decide not to take care. Thus, availability of the defense of contributory negligence might turn out to be undesirable. (The more general point here is that a liability rule which induces the second party to take care regardless of whether the first party took care might turn out to be desirable.) This possibility is briefly examined in an extension of the model.

Before proceeding, it should be remarked that although the analysis in the next section will be informal and will rely primarily on numerical examples, the claims made will be proved in general in the subsequent section. ${ }^{11}$

II. Informal Analysis of the Model

A. Description of the model

As Figure 1 shows, in one case of the model, the victim first decides whether to take care so as to reduce the likelihood of occurrence of a dangerous condition; and if such a condition arises, the injurer then decides whether to take care in order to reduce the risk of an accident. ${ }^{12}$ (The case of the model where the injurer acts first is analogous and will not be separately described.)

The victim will take care if the cost of doing so plus the probability-discounted or "expected" losses $^{13}$ he would then bear is less than the expected losses he would bear if he does not take care. To make this comparison, the victim must determine whether, given the liability rule, the 
$4 \pi$

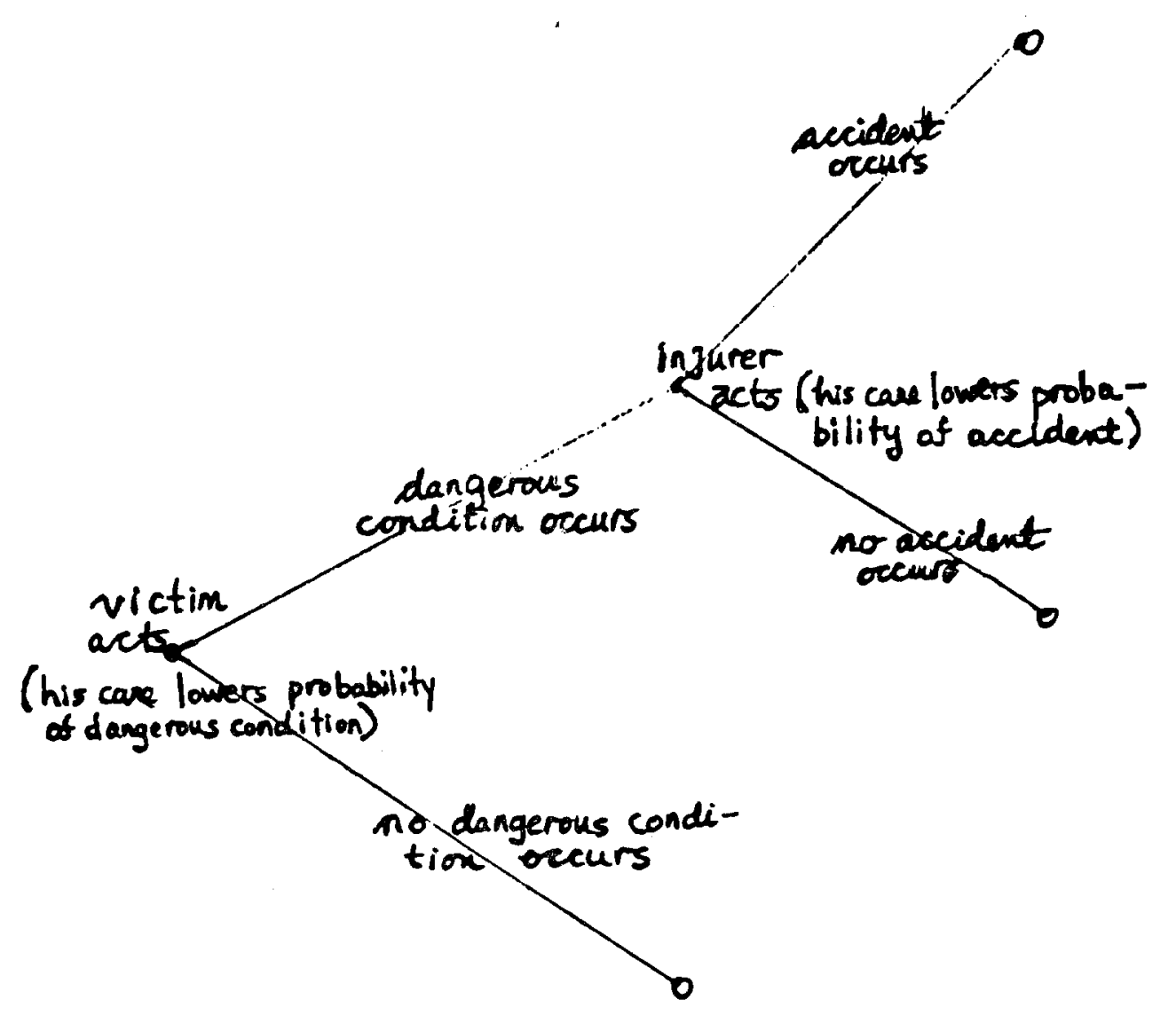

Sequence of Actions (case where victims act before injurers)

Figure 1 
injurer will take care if a dangerous condition arises, for this would affect the likelihood of loss and, possibly, liability for loss.

The injurer will take care when a dangerous condition arises if his cost of care plus his expected liability given the liability rule is less than his expected liability if he does not take care. In making this decision, the injurer is assumed to be aware of whether or not the victim took care. ${ }^{14}$

B. Ideal solution to the accident problem

It will be assumed that the ideal solution to the accident problem is to minimize total costs, that is, to minimize the expected sum of accident losses and the victim's and injurer's costs of care. The actions of the victim and of the injurer that minimize total costs will be referred to as "optimal."

Let us now consider the determination of the parties' optimal actions using as an example the situation shown in Table 1. ${ }^{15}$ In doing this it will be convenient to refer also to the derived Table 2, the first row which is explained as follows. Since both parties take care, .10 is the probability of a dangerous condition, 0 is the probability of an accident given occurrence of a dangerous condition, .10 $00=0$ is the likelihood of an accident, and $0 \times 1000=0$ are expected losses; the victim's cost of care is 10 and the injurer's expected cost of care is $.10 \times 200=20$ (the injurer takes care only when a dangerous condition arises), so the sum of 
Probability of dangerous condition

Victim does not take care .20

Victim takes care

.10

Probability of accident given occurrence of dangerous condition

Injurer does not take care .50

Injurer takes care

0

Cost of care

Victim 10

Injurer 200

Victim's loss if there is an accident 1000

Table 1 


\begin{tabular}{|c|c|c|c|c|c|c|c|}
\hline $\begin{array}{l}\text { 'ictim's } \\
\text { action }\end{array}$ & $\begin{array}{l}\text { Injurer's } \\
\text { action }\end{array}$ & $\begin{array}{l}\text { Probability } \\
\text { of dangerous } \\
\text { condition }\end{array}$ & $\begin{array}{l}\text { Probability } \\
\text { of accident } \\
\text { given dangerous } \\
\text { condition }\end{array}$ & $\begin{array}{l}\text { Probability } \\
\text { of } \\
\text { accident } \\
\end{array}$ & $\begin{array}{l}\text { Expected } \\
\text { losses } \\
\end{array}$ & $\begin{array}{l}\text { Expected } \\
\text { costs of } \\
\text { care } \\
\end{array}$ & $\begin{array}{l}\text { Expected } \\
\text { total } \\
\text { costs } \\
\end{array}$ \\
\hline :are & care & .10 & 0 & 0 & 0 & 30 & 30 \\
\hline :are & no care & .10 & .50 & .05 & 50 & 10 & 60 \\
\hline to care & care & .20 & 0 & 0 & 0 & 40 & 40 \\
\hline lo care & no care & .20 & .50 & .10 & 100 & 0 & 100 \\
\hline
\end{tabular}

Table 2 
their expected costs of care is 30; hence expected total costs are 30 . The other rows are explained similarly.

Given the tabulation of expected total costs in Table 2, we can see that what minimizes these costs is for both the victim and the injurer to take care. ${ }^{16}$ To understand why this should be so, observe first that it is best for the injurer to take care if a dangerous condition arises, since the cost of care of 200 is less than the associated reduction in expected accident costs given occurrence of the dangerous condition of $.50 \times 1000=500$. And to see why it is best for the victim to take care, notice that the cost of creating a dangerous condition given that the injurer responds optimally by taking care is the injurer's cost of care, namely, 200 . Hence, by taking care and incurring a cost of 10 , the victim reduces the injurer's expected costs of care from $.20 \times 200$ $=40$ to $.10 \times 200=20$, and thus lowers expected total costs by 20 .

This numerical example may also be used to illustrate the case where injurers act first, by reversing the roles of injurer and of victim (so the victim's cost of care if a dangerous condition arises becomes 200, etc.).

C. Solution to the accident problem under liability rules

1. Case where victims act first

Let us now determine how the victim and the injurer will act under the various liability rules. This will be done using the numerical example that was just discussed. 
First, let us consider the negligence rule with a defense of contributory negligence. According to this rule, the injurer is liable for losses if and only if he failed to take care (i.e., was negligent) and the victim took care (i.e., was not negligent). We wish to demonstrate that under this rule an optimal outcome will result; both the victim and the injurer will take care. To do this, observe that if the victim does not take care, then the injurer will escape liability for an accident whether or not he takes care, so he will clearly decide against taking care if a dangerous condition arises. However, if the victim takes care, then if a dangerous condition arises and the injurer fails to take care, he will face expected liability of $.50 \mathrm{x}$ $1000=500$. Thus, as the cost of care to him is only 200, the injurer will choose to escape liability by taking care. With this in mind, the victim's decision may be determined. If the victim does not take care, he will bear his losses, and since he knows that the injurer will not take care if a dangerous condition arises, the victim's expected losses will be $.20 \times .50 \times 1000=100$. But since the injurer will take care if the victim takes care, his costs will be only his costs of care, 10. Hence the victim will take care, which completes the argument.

The reasoning used in this demonstration, it should be noted, was indeed that indicated in the introduction. Namely, the victim is induced to take care for fear of the losses he would bear if he were negligent--since then the 
injurer would not take care; and as the victim decides to take care, the injurer will in fact be induced to take care if a dangerous condition arises.

Let us next consider the negligence rule without a defense of contributory negligence. Under this rule, according to which the injurer is liable if and only if he failed to take care, an optimal outcome will not occur; the victim will not take care, although the injurer will take care if a dangerous condition arises. ${ }^{17,18}$ To show this, note that if a dangerous condition arises and the injurer does not take care, he will be liable for losses, independent of whether the victim took care. Accordingly, the injurer's expected liability will be $.50 \times 1000=500$. As this exceeds his cost of care of 200, the injurer will decide to take care. with regard to the victim's situation, observe that he knows by the above reasoning that the injurer will take care if a dangerous condition arises and thus that the possibility of an accident will be eliminated. Hence the victim will have no reason to incur costs of care of 10 and will not do so. ${ }^{19}$

The victim's negligence may be explained slightly differently by noting the difference between his private problem--minimizing his own costs under the liability rule-and his problem from the social viewpoint--minimizing expected total costs. From the victim's private perspective, the occurrence of dangerous conditions is costless and thus need not be prevented, whereas from the social perspective they 
are costly, as they result in the injurer's exercise of care, and hence should be prevented. 20

Let us now summarize the situation in respect to the other two liability rules. According to the comparative negligence rule the injurer pays full damages for losses if he alone failed to take care, but pays only a fraction $f$ of damages if the victim too did not take care. Under this rule an optimal outcome may not result. The reason is that if $\underline{f}$ is not small, the injurer might find it worthwhile to take care if a dangerous condition arises whether or not the victim took care. And if this is the case, then the victim might decide not to take care. 21

Finally, under strict liability with a defense of contributory negligence, the injurer is liable unless the victim did not take care. Under this rule an optimal outcome will occur, and for essentially the reasons applying under the negligence rule with a defense of contributory negligence. In particular, the victim will take care, since if he did not, the injurer would fail to take care; and as the victim takes care, the injurer is also motivated to take care if a dangerous condition arises so as to avoid liability. 22

In conclusion, let us state what may be taken to be the general principle underlying the results that have been presented: a liability rule results in optimal behavior provided that it induces the party who acts second to take care when a dangerous condition arises if and only if the 
first party took care; for this will induce the first and, therefore, the second party to take care.

\section{2. case where injurers act first}

Here it will be seen that although the conclusions about the liability rules are different, they are nevertheless consistent with the general principle just mentioned.

Consider for instance the first result to be shown, that under the negligence rule without the defense of contributory negligence, an optimal outcome will result. This result is indeed consistent with the general principle, for not allowing the defense of contributory negligence will mean that the victim--now the party who acts second--will take care if and only if the injurer took care.

Let us demonstrate the result using the numerical example (with the roles of injurer and of victim reversed). To do this, consider first the victim's position when a dangerous condition arises. If the injurer took care, then if the victim fails to take care, he will bear his own expected losses of . $50 \times 1000=500$, whereas if he takes care, he bears only his costs of care of 200 . Thus, the victim will take care. On the other hand, if the injurer did not take care, then the victim will have no motive to take care, there being no defense of contributory negligence available to the injurer. In consequence, the injurer (and thus the victim) will choose to take care: if the injurer does not take care, his expected liability will be $.20 \times .50$ 
$\mathbf{x} 1000=100$ since the victim will not take care; and if the injurer does take care, he will not be liable and thus bear only his costs of care of 10 .

Let us now briefly explain the conclusions about the other liability rules. Under the negligence rule with a defense of contributory negligence, an optimal outcome will not result. This is true because, when dangerous conditions arise, victims will always be induced to take care so as to avoid bearing losses. And since the injurer knows this to be true, he will find it worthwhile not to take care. ${ }^{23}$

For similar reasons, under the comparative negligence rule, an optimal outcome might not be achieved; and under strict liability with a defense of contributory negligence, an optimal outcome will not be achieved.

D. An Extension of the Model

We now wish to consider a modification of the model towards greater realism. As indicated in the introduction, this may reverse the general conclusion of the last subsection that it is best to employ liability rules which give the party who acts second a motive to take care if and only if the first party exercised care.

The modification concerns the possibility that the party who acts first might be "inevitably" negligent--fail to take care regardless of the liability rule--because he overlooks the risk of an accident. It will be sufficient for us to examine the possibility of such inevitable negligence 
only in the case where the victim acts first and only in relation to the negligence rule (our analysis will carry over in an obvious way to the other case and in relation to the other liability rules).

To understand the importance of possible inevitable negligence in this case, recall that the advantage in the basic model of allowing the defense of contributory negligence was to give victims a motive to take care. If, however, a number of victims will inevitably act negligently, then in respect to affecting the behavior of these victims, allowing the defense of contributory negligence will by assumption fail to secure an advantage. Moreover, because these victims will act negligently, allowing the defense will lead injurers to fail to take care (a problem which, note, did not exist in the basic model simply because there were no negligent victims). Therefore, it may turn out to be desirable not to allow the defense of contributory negligence. 24

To illustrate this, let us reexamine the numerical example assuming, say, .2 of victims mistakenly ignore all chance of loss and thus will fail to take care whatever the liability rule. Then, from Table 3 and Table 2 it can be seen that if there is a defense of contributory negligence, the total expected costs will be .2 $\times 100+.8 \times 30=44$ (taking the average over situations involving both types of victim); and from Table 4 and Table 2 it is clear that these costs will be 40 if there is not a defense. Hence, it is better that there not be a defense of contributory negligence. 25 
Behavior Under The Negligence Rule with a Defense of Contributory Negligence*

\begin{tabular}{lcl} 
& Victim's action & Injurer's action \\
\hline Victim ignores risk & no care & no care \\
\hline Victim understands risk & care & care \\
\hline
\end{tabular}

*case where victim acts first

Table 3 
$12 b$

Behavior Under The Negligence Rule without a

Defense of Contributory Negligence*

\begin{tabular}{lcl} 
& Victim's Action & Injurer's Action \\
\hline Victim ignores risk & no care & care \\
\hline Victim understands risk & no care & care \\
\hline
\end{tabular}

* case where victims act first

Table 4 
Notice, as expected, that the figures show that the result came about because when victims ignore the risk, the defense of contributory negligence results in higher costs (100) than does absence of the defense (40).

Finally, let us remark that this example did not allow for the possibility that injurers too might inevitably act negligently, a possibility which would lead to a qualification of the point of the present subsection. The main reason for the qualification is of course that the advantage of not employing the defense of contributory negligence--inducing injurers to take care when victims have not--can hardly be enjoyed when injurers will inevitably act negligently. 26 But the qualification will not be very important if the probability of inevitable negligence on the part of injurers is much less than it is on the part of victims. And this might be thought the case, for the nature of the situation facing the party who acts second is typically such that the danger is obvious and thus not likely to be overlooked, whereas the situation facing the party who acts first is often such that the danger is not clear or is remote.

III. Formal Analysis of the $\underline{\text { Model }}^{27}$

A. Description of the model

As the model has been discussed informally, we can be brief here. There are two types of risk-neutral parties, victims and injurers. In one of the cases that is examined, 
the victim first decides whether to take care; if a dangerous condition then arises, the injurer decides whether to take care, and an accident either occurs or fails to occur. (See Figure 1.) In the other case, the injurer acts before the victim. In each case, the first-best or expected total cost minimizing levels of care of the parties are determined; and the effects of liability rules on parties' behavior are also determined, assuming that the party who acts second can observe whether the first party took care.

A. Case where victims act first

Define the following notation.

$\mathbf{x}=$ cost of care for a victim; $\mathbf{x}>0$;

$\mathrm{p}_{\mathrm{C}}=$ probability of a dangerous condition if victim takes care;

$p_{n}=$ probability of a dangerous condition if victim does not take care; $\mathrm{p}_{\mathrm{n}}>\mathrm{p}_{\mathrm{C}} \geqq 0$;

$\mathrm{y}=$ cost of care for an injurer; $\mathrm{y}>0$;

$\mathrm{q}_{\mathrm{C}}=$ probability of an accident given that there is a dangerous condition if the injurer takes care;

$\mathrm{q}_{\mathrm{n}}=$ probability of an accident given that there is a dangerous condition if the injurer does not take care; $q_{n}>q_{C} \geqq 0$.

$\ell=$ loss if an accident occurs; $\ell>0$.

The variables $x, y$, and $\ell$ are assumed to be monetary. The measure of social welfare is (the negative of) expected total costs--the expected costs of care plus expected accident losses. Thus, if both parties take care, total costs are

(1) $x+p_{C}\left(y+q_{C} l\right)$; 
if the victim alone takes care, total costs are

(2) $\mathrm{x}+\mathrm{p}_{\mathrm{c}} \mathrm{q}_{\mathrm{n}} \ell$;

if the injurer alone takes care, total costs are

(3) $p_{n}\left(y+q_{C} \ell\right)$;

and if neither party takes care, total costs are

(4) $p_{n} q_{n} \ell$.

We will be interested mainly in the situation where it is strictly optimal for both parties to take care (i.e., where (1) is the unique minimum among (1)-(4)) but we will also consider the situations where it is strictly optimal for the injurer alone to take care (where (3) is the unique minimum) and where it is strictly optimal for the victim alone to take care (where (2) is the unique minimum). (Henceforth, by "optimal", we shall mean strictly optimal.)

Let us now define the liability rules using (as is customary) so called due care levels for victims and for injurers. Specifically, define the rules as follows. Under the negligence rule with the defense of contributory negligence, an injurer is liable for loss if and only if he took less than due care and the victim took at least due care. Under the negligence rule without the defense of contributory negligence, an injurer is liable for loss if and only if he took less than due care. Under the comparative negligence rule, an injurer is liable for (the entire) loss if and only if he took less than due care and the victim took at least due care; and an injurer is partially liable--for a fraction $f$ where $0<f<1$ of loss--if and only if both he and the victim 
took less than due care. (This is the only rule under which the injurer is partially liable.) And, under strict liability with a defense of contributory negligence, an injurer is liable for loss if and only if the victim took at least due care.

Let us now assume that it is optimal for victims and for injurers to take care and that what constitutes due care for each is to take care. We then have

Proposition 1. Under the negligence rule with a defense of contributory negligence, an optimal outcome will be achieved; both the victim and the injurer will take care.

Proof: If the victim does not take care and a dangerous condition arises, the injurer will not take care because he will never be liable. Thus the victim's expected cost will be $p_{n} q_{n} l$.

If the victim does take care and a dangerous condition arises, the injurer will take care in order to avoid liability: if the injurer takes care, his costs will be $y$; if he does not, they will be $q_{n} l$; and since it is optimal for both to take care, we know in particular that $x+p_{C}\left(y+q_{C} l\right)<x+$ $p_{c} q_{n} l$, which implies that $y+q_{C} l<q_{n} l$, which implies that $\mathrm{y}<\mathrm{q}_{\mathrm{n}} \ell$. As the injurer will take care, the victim's expected costs will be $x+p_{c} q_{c} l$.

Thus the victim will decide to take care: since it is optimal for both to take care, we know in particular that $\mathbf{x}$ $+p_{c}\left(y+q_{c} \ell\right)<p_{n} q_{n} l$, so certainly $x+p_{c} q_{c} \ell<p_{n} q_{n} \ell$. 
This completes the demonstration, since we showed that if the victim takes care, so will the injurer should a dangerous condition arise. Q.E.D.

Proposition 2. Under the negligence rule without the defense of contributory negligence, an optimal result may not be achieved; the victim might fail to take care although the injurer will take care if a dangerous condition arises. ${ }^{28}$ Proof: If the victim does not take care and a dangerous condition arises, then the injurer will take care and avoid liability: if the injurer takes care, his costs will be $y$; if he does not, they will be $q_{n} \ell$; but $y<q_{n} \ell$ (as was shown in the proof to Proposition 1). Thus the victim's expected costs will be $p_{n} q_{C} l$.

If the victim does take care and a dangerous condition arises, the injurer will by the same logic take care so as to avoid liability. Hence the victim's expected costs will be $x+p_{c} q_{c} \hat{l}$.

It is possible that $x+p_{C} q_{C} \ell>p_{n} q_{C} l$ even though $x+$ $\mathrm{p}_{C}\left(\mathrm{y}+\mathrm{q}_{\mathrm{C}} \ell\right)$ minimizes total costs; this was true in the numerical example of the previous section, and, indeed, will always be true if $\mathrm{q}_{\mathrm{C}}=0$. Thus, the victim might not take care, although the injurer will do so if a dangerous condition arises. Q.E.D.

Proposition 3. Under the comparative negligence rule, an optimal result may not be achieved; the victim alone or 
the victim and the injurer both may fail to take care, although the injurer alone will never fail to take care if a dangerous condition arises.

Proof: The numerical example of the last section with $f=.5$ is such that the injurer will take care but the victim will not. (See in particular note 21 supra).

An example where neither party takes care is the following: $\mathrm{x}=35 ; \mathrm{p}_{\mathrm{n}}=.2 ; \mathrm{p}_{\mathrm{C}}=.1 ; \mathrm{y}=190 ; \mathrm{q}_{\mathrm{n}}=.4 ; \mathrm{q}_{\mathrm{C}}=.2 ; \ell=1000 ; \mathrm{f}=.4$. To verify this, note that if the victim does not take care, the injurer will not (for 190>(.4)(.4)(1000)), so the victim's expected costs will be $(.2)(.4)(600)=48$. And if the victim does take care, the injurer will as well (for 190<(.4)(1000)), so that the victim's expected costs will be $35+(.1)(.2)(1000)=55$, which exceeds 48 .

Finally, if the victim takes care, so will the injurer, since $y<q_{n} l$ (as was shown in the proof to Proposition 1 ). Q.E.D.

Proposition 4. Under strict liability with a defense of contributory negligence, an optimal outcome will be achieved; both the victim and the injurer will take care. Proof. If the victim does not take care and a dangerous condition arises, the injurer will not take care since he will not be liable. Hence the victim's expected costs will be $p_{n} q_{n} l$.

If the victim does take care and a dangerous condition arises, the injurer will take care; since he will be liable 
for losses, his costs will be $y+q_{c} l$ if he takes care and $q_{n} \ell$ if not; but $y+q_{C} \ell<q_{n} \ell$ (as was shown in the proof to Proposition 1 ). Hence the victim's costs will be $x$.

Since it is optimal for both the injurer and the victim to take care, we know that $x+p_{C}\left(y+q_{C} \ell\right)<p_{n} q_{n} l$; thus certainly $x<p_{n} q_{n} \ell$. Hence the victim will take care, and if a dangerous condition arises, so will the injurer. Q.E.D.

Let us now briefly consider the situation where it is optimal for only one of the parties to take care. If it is optimal for the injurer alone to take care, let us assume that what constitutes due care for him is to take care, but that due care for the victim is zero. Hence both versions of the negligence rule and the comparative negligence rule will all be identical: the injurer will be liable for losses if and only if he fails to take care. Also, under the strict liability rule with the defense of contributory negligence, the injurer will always be liable. Similarly; if it is optimal for the victim alone to take care and we assume that due care levels reflect this, then all versions of the negligence rule will be identical--the victim will always be liable. With this in mind let us state

Remark 5. In the situations where it is optimal for the injurer alone to take care or for the victim alone to take care, an optimal outcome will result under any of the liability rules. 
Proof: Consider first the situation where it is optimal for injurers alone to take care. Then under (any of the three versions of) the negligence rule, if a dangerous condition arises, the injurer will avoid liability and take care: since $p_{n}\left(y+q_{c} l\right)$ minimizes total costs, $p_{n}\left(y+q_{c} l\right)<p_{n} q_{n} l$ so that $y<q_{n} l$. Thus, if the victim does not take care, his expected costs will be $p_{n} q_{C} l$; if he does take care, they will be $\mathrm{x}+\mathrm{p}_{\mathrm{C}} \mathrm{q}_{\mathrm{C}} l$; and since $\mathrm{p}_{\mathrm{n}}\left(\mathrm{y}+\mathrm{q}_{\mathrm{C}} \ell\right)<\mathrm{x}+\mathrm{p}_{\mathrm{C}}\left(\mathrm{y}+\mathrm{q}_{\mathrm{C}} \ell\right)$ and $\mathrm{p}_{\mathrm{n}}$ $>p_{c^{\prime}}$ we have $p_{n} q_{C} l<x+p_{C} q_{C} l$. Hence the victim will not take care.

Under strict liability with the defense of contributory negligence, as the injurer will always be liable, he will take care if a dangerous condition arises: since we know that $\mathrm{p}_{\mathrm{n}}\left(\mathrm{y}+\mathrm{q}_{\mathrm{C}} l\right)<\mathrm{p}_{\mathrm{n}} \mathrm{q}_{\mathrm{n}} l$, we have $\mathrm{y}+\mathrm{q}_{\mathrm{C}} \ell<\mathrm{q}_{\mathrm{n}} l$. And, clearly, the victim will not take care.

Now consider the situation where it is optimal for the victim alone to take care. Then under (any of the three versions of) the negligence rule, the injurer will never be liable and so will not take care. Hence, if the victim does not take care, his expected costs will be $p_{n} q_{n} l$; if he does, they will be $x+p_{C} q_{n} l$; but the latter is less than the former since $x+p_{c} q_{n} l$ minimizes total costs.

Under strict liability with the defense of contributory negligence, if the victim fails to take care, he will be liable, so the injurer will not take care. Hence the victim's expected costs will be $p_{n} q_{n} l$. If the victim takes care, then the injurer will be liable, so the victim's expected 
costs will be $x$. And as we know that $x+p_{C} q_{n} \ell$ minimizes total costs, $x+p_{c} q_{n} l<p_{n} q_{n} l$, so $x<p_{n} q_{n} l$. Thus the victim will take care. But the injurer will not do so if a dangerous condition arises: since $x+p_{c} q_{n} l$ minimizes total costs, $x+p_{C} q_{n} \ell<x+p_{C}\left(y+q_{C} \ell\right)$, implying that $q_{n} \ell<y+q_{C} \ell$. Q.E.D.

\section{B. Case where injurers act first}

In this case the notation will be defined as in the last case, but the formulas for total costs will be different: If both parties take care, then total costs are

(5) $y+q_{C}\left(x+p_{C} l\right)$;

if the injurer alone takes care, they are

(6) $\mathrm{y}+\mathrm{q}_{\mathrm{C}} \mathrm{p}_{\mathrm{n}} \mathrm{n}$;

if the victim alone takes care, they are

(7) $q_{n}\left(x+p_{c} l\right)$;

and if neither party takes care they are

(8) $q_{n} p_{n} \ell$.

Let us now consider the liability rules assuming that it is optimal for injurers and for victims to take care and that what constitutes due care for each is the exercise of care. (Since the proofs are analogous to those of Propositions 1-4 and Remark 5, we will supply as a pattern for the reader the proof to the next Proposition only).

Proposition 6. Under the negligence rule with a defense of contributory negligence, an optimal outcome may not be achieved; the injurer might fail to take care although the victim will take care if a dangerous condition arises. 
Proof: If the injurer does not take care and a dangerous condition arises, then the victim will take care to avoid bearing his losses: if the victim takes care, his costs will be $x$; if he does not, they will be $p_{n} l$; and since it is optimal for both parties to take care, we know that $y+$ $\mathrm{q}_{C}\left(\mathrm{x}+\mathrm{p}_{\mathrm{C}}{ }^{\ell}\right)<\mathrm{y}+\mathrm{q}_{\mathrm{C}} \mathrm{p}_{\mathrm{n}}{ }^{l}$, implying that $\mathrm{x}+\mathrm{p}_{\mathrm{C}}{ }^{\ell}<\mathrm{p}_{\mathrm{n}}^{\ell}$, so that $\mathrm{x}<\mathrm{p}_{\mathrm{n}} \boldsymbol{l}$. Thus the injurer's expected costs will be $\mathrm{q}_{\mathrm{n}} \mathrm{p}_{\mathrm{c}}{ }^{\ell}$.

If the injurer does take care and a dangerous condition arises, then the victim will again take care: if he takes care, his expected costs will be $x+p_{C} l$; if he does not, they will be $p_{n} l$; and as shown above, $x+p_{c} c^{l} p_{n} l$. The injurer's costs in this case will be $y$.

It is possible that $y>q_{n} p_{c} l$ even though $y+q_{C}\left(x+p_{c} l\right)$ minimizes total costs; indeed, $y>q_{n} p_{c} l$ will necessarily be true if $p_{C}=0$.

Hence, we have shown that the injurer might not take care but that the victim will if a dangerous condition arises. Q.E.D.

(The proof was analogous to that of Proposition 2).

Proposition 7. Under the negligence rule without a defense of contributory negligence, an optimal outcome will be achieved; both the injurer and the victim will take care.

(The proof is analogous to that of Proposition 1).

Proposition 8. Under the comparative negligence rule, an optimal result may not be achieved; the injurer alone or the 
injurer and the victim both may not take care, although the victim will do so if the injurer takes care and a dangerous condition arises.

(The proof is analogous to that of Proposition 3 ).

Proposition 9. Under strict liability with a defense of contributory negligence, an optimal outcome may not be achieved; the injurer may fail to take care, although the victim will do so if a dangerous condition arises.

(The proof is similar to that of Proposition 2).

Remark 10. In the situations where it is optimal for the injurer alone or for the victim alone to take care, an optimal outcome will result under any of the liability rules.

(The proof is analogous to that of Remark 5).

C. Extension of the model

As explained in section II, the extension of the model to be considered concerns the possibility that parties would ignore the risk of an accident. It will suffice to examine the effect of overlooking risk in only one case; this case will supply the necessary insight for analysis of the other cases, which would be tedious. The case of interest is that where victims act first; where it is optimal for both parties to take care; and where in the absence of ignorance of risk, the negligence rule with the defense of contributory negligence 
would be superior to the negligence rule without the defense, because under the latter rule victims would fail to take care (see Propositions 1 and 2 ). We wish now to determine which of these two rules is superior as a function of $\alpha$ and $\beta$, where

$$
\begin{aligned}
\alpha= & \text { fraction of victims who ignore risk, believing it } \\
& \text { to be zero; } 0 \leqq \alpha \leqq 1 ; \\
\beta= & \text { fraction of injurers who ignore risk, believing it } \\
& \text { to be zero; } 0 \leqq \beta \leqq 1 .
\end{aligned}
$$

We will assume that the events that a victim ignores risk and that an injurer who finds a victim in a dangerous situation ignores risk are probabilistically independent.

Let us observe first that Tables 5 and 6 below describe the behavior of parties under the two rules, and independent of the values of $\alpha$ and $\beta$. Let us explain several of the entries in Table 5, leaving the verification of the remainder of the entries in the tables to the reader. As a party who thinks the risk of a dangerous condition or an accident is zero will not take care, many of the entries in the tables are immediately explained. Thus, the first row of Table 5 is explained, as is the first entry in the second row of Table 5. The second entry in the second row is then clear: as the victim does not take care, he will bear his losses, so the injurer will not take care.

The first entries in the third and fourth rows of Table 5 are explained as follows: If a victim takes care and a dangerous condition arises, then the injurer will not take 
Behavior Under the Negligence Rule With A Defense of Contributory Negligence*

Victim's

Injurer's

action action

Victim and injurer

ignore risk

no care

no care

Victim alone

ignores risk

no care

no care

Injurer alone

ignores risk

care

no care

Neither party

ignores risk

care

care

$\star$

case where victim acts first

Table 5 
Behavior Under The Negligence Rule Without a Defense of Contributory Negligence*
Victim's action
Injurer's action

Victim and injurer

ignore risk

no care

no care

Victim alone

ignores risk

no care care

Injurer alone

ignores risk

no care

no care

Neither party

ignores risk

no care

care

*case where victim acts first

Table 6 
care (and will bear liability) if he ignores the risk, but he will take care if he perceives it (as was demonstrated in the proof to Proposition 1). Hence the victim's expected position will be $x+p_{C}(1-\beta) q_{C} l$. On the other hand, if the victim does not take care and a dangerous condition arises, then the injurer will not take care if he correctly perceives the risk (as was shown in the proof to Proposition 1) or if he ignores it. Hence the victim's expected position will be $p_{n} q_{n} l$. But $x+p_{C}(1-\beta) q_{c} \ell<x+p_{C}\left(y+q_{C} l\right)<p_{n} q_{n} l$, so that the victim will take care.

Using the tables, we may write the formulas for expected total costs. Under the negligence rule with the defense of contributory negligence, the expected total costs are

$$
\text { (9) } \begin{aligned}
\alpha \beta p_{n} q_{n} l+\alpha(1-\beta) p_{n} q_{n} l+(1-\alpha) \beta\left(x+p_{C} q_{n} l\right)+ \\
(1-\alpha)(1-\beta)\left(x+p_{C}\left(y+q_{C} l\right)\right)=\ell\left(\alpha p_{n} q_{n}+(1-\alpha) \beta p_{C} q_{n}+\right. \\
\left.(1-\alpha)(1-\beta) p_{C} q_{C}\right)+(1-\alpha) x+(1-\alpha)(1-\beta) p_{C} y .
\end{aligned}
$$

Under the negligence rule without the defense, expected total costs are

$$
\begin{aligned}
& \text { (10) } \alpha \beta p_{n} q_{n} \ell+\alpha(1-\beta) p_{n}\left(y+q_{c} l\right)+(1-\alpha) \beta p_{n} q_{n} l+ \\
& (1-\alpha)(1-\beta) p_{n}\left(y+q_{C} l\right)=\ell\left(\beta p_{n} q_{n}+(1-\beta) p_{n} q_{C}\right)+(1-\beta) p_{n} y .
\end{aligned}
$$

Hence, the negligence rule with the defense of contributory negligence will be superior or inferior to the rule without the defense according as (9) is less than or greater than (10), or as

$$
\text { (11) } \begin{aligned}
& \ell\left((\alpha-\beta) p_{n} q_{n}+(1-\alpha) \beta p_{C} q_{n}+(1-\alpha)(1-\beta) p_{C} q_{C}-(1-\beta) p_{n} q_{C}\right) \\
+ & (1-\alpha) x+\left((1-\alpha)(1-\beta) p_{C}-(1-\beta) p_{n}\right) y>0
\end{aligned}
$$


It follows from this formula that for any $\beta<1$, there exists an $\alpha$ sufficiently high that the negligence rule without the defense of contributory negligence is superior to the rule with the defense. (The sense behind this result was explained in the previous section.) To see this, observe that if $\beta<1$ and $\alpha=1$, the left-hand-side of (11) is

$$
\begin{aligned}
& \text { (12) } \ell\left((1-\beta) p_{n} q_{n}-(1-\beta) p_{n} q_{C}\right)-(1-\beta) p_{n} y= \\
& (1-\beta) p_{n}\left(q_{n} \ell-\left(y+q_{c} \ell\right)\right)>0
\end{aligned}
$$

for $y+q_{c} l<q_{n} \ell$ since it is optimal for the injurer to take care. 


\section{Appendix}

The model analyzed above will be reconsidered here assuming that victims and injurers choose continuously variable levels of care. This version of the model is of interest for two reasons: it sometimes provides a better description of reality, as many aspects of care do seem continuously variable (e.g., in Davies, the distance between the fettered donkey and the shoulder of the road); and it is in conformity with most of the literature studying microeconomic models of accidents and liability. 29 It will be seen that although the analysis of the continuous version of the model is more complicated than that of the model considered above, 30 the results will be essentially unaltered.

A. Case where victims act first

Let the variables $\ell, x$, and $y$ be defined as before (but now $x$ and $y$ are continuously variable) $)^{31}$ and let

$\mathrm{p}(\mathrm{x})=$ probability of a dangerous condition;

$1>\mathrm{p}>0 ; \mathrm{p}^{\prime}<0 ; \mathrm{p}^{\prime \prime}>0 i^{32}$

$q(y, x)=$ probability of an accident given that a dangerous condition has arisen and given $y$ and $\mathrm{x} ; 1>\mathrm{q}>0 ; \mathrm{q}_{\mathrm{y}}<0 ; \mathrm{q}_{\mathrm{YY}}>0 ; \mathrm{q}_{\mathrm{x}} \leqq 0 ; \mathrm{q}_{\mathrm{xy}}$ $\geqq 0.33$

The measure of social welfare will be (the negative of) expected total costs,

(13) $\mathrm{T}(\mathrm{x}, \mathrm{y})=\mathrm{x}+\mathrm{p}(\mathrm{x})(\mathrm{y}+\mathrm{q}(\mathrm{y}, \mathrm{x}) \ell)$. 
Let $x^{*}$ and $y *$ denote the values of $x$ and $y$ which minimize $T$, and let $y^{*}(x)$ denote the value of $y$ that minimizes

(14) $y+q(y, x) \ell$.

(Note, therefore, that $\left.y^{*}=y\left(x^{*}\right).\right)$ These optimal values will be assumed to be positive and unique. Additionally, we will assume in certain of the proofs that various functions are convex, although somewhat weaker assumptions would suffice.

Let us now determine the behavior of parties under liability rules. In doing so, let us define

$$
\begin{aligned}
y(x)= & \text { injurer's choice of } y \text { given the victim's } \\
& \text { choice of } x \text { and the liability rule; }
\end{aligned}
$$

in other words, $y(x)$ minimizes the injurer's cost of care $y$ plus his expected liability given $x$ (which, recall, the injurer observes) and given the liability rule. With $y(x)$, the victim's choice of $x$ can be determined; he minimizes his cost of care $x$ plus his expected losses given the injurer's response $\mathrm{y}(\mathrm{x})$ and the liability rule. 34

Let us assume that the due care levels are the optimal levels of care: the due care level for victims is $x^{*}$, and for injurers it is $y^{*}(x)$. We may now consider the liability rules. (The definitions of the rules given in section III will serve here.)

Proposition $11 .{ }^{35}$ Under the negligence rule with the defense of contributory negligence, an optimal outcome will be achieved; both the victim and the injurer will choose optimal levels of care. 
Proof. We wish to show that $x^{\prime}=x^{*}$ and $y=y^{*}$. Let us first determine $y(x)$ under the liabi'ity rule. To do this, note on the one hand that $x<x^{*}$ implies $y(x)=0$, for if $x<x^{*}$, the injurer will not be liable. On the other hand, $\mathrm{x} \geqq \mathrm{x}$ * implies $y(x)=y^{*}(x)$. This may be shown by a standard argument. Namely, if the injurer chooses $y \geqq y^{\star}(x)$, as he will not be liable, his costs will be $y$; thus he will certainly choose $y=y^{*}(x)$. And if he chooses $y<y^{*}(x)$, as he will be liable, his problem will be to minimize $y+q(y, x) l$ over $y<y^{*}(x)$; but, by definition of $y^{*}(x)$,

(15) $y+q(y, x) \ell>y^{*}(x)+q(y *(x), x) \ell>y^{*}(x)$ for $y \neq y^{*}(x)$, and in particular for $y<y^{*}(x)$. Hence the injurer will choose $y^{\star}(x)$.

Let us now prove that the victim will choose $x^{*}$. Since $y(x)=y^{*}(x)$ for $x \geqq x^{*}$, the victim will always bear his losses. Thus his problem is

$$
\begin{aligned}
& \text { (16) } \min _{x} x+p(x) q(y(x), x) \ell=\underset{x<x^{*}}{\min \left(\min _{x} x+p(x) q(0, x) \ell,\right.} \\
& \left.\min _{x \geqq x^{*}}+p(x) q\left(y^{*}(x), x\right) \ell\right) .
\end{aligned}
$$

However,

$$
\text { (17) } \begin{aligned}
& \min _{x<x^{\star}} x+p(x) q(0, x) \ell=\min _{x<x^{\star}} x+p(x)(0+q(0, x) \ell) \\
> & \min _{x, y}+p(x)(y+q(y, x) \ell)=x^{\star}+p\left(x^{\star}\right)\left(y^{\star}+q\left(y^{\star}, x^{\star}\right) \ell\right) \\
> & x^{\star}+p\left(x^{\star}\right) q\left(y^{\star}, x^{\star}\right) \ell=x^{\star}+p\left(x^{\star}\right) q\left(y^{\star}\left(x^{\star}\right), x^{\star}\right) \ell \\
\geqq & \min _{x \geqq x^{*}} x+p(x) q\left(y^{\star}(x), x\right) \ell .
\end{aligned}
$$


Hence the $x$ that solves (16) must be greater than or equal to $x^{*}$. Thus, to prove that the solution is $x^{*}$, it will clearly suffice to show that the derivative of $x+p(x) q\left(y^{*}(x), x\right) l$ is positive for $x \geqq x^{*}$. But this will be seen to follow from an assumption that the problem of minimizing $T\left(x, y^{*}(x)\right)=x$ $+p(x)\left(y^{*}(x)+q\left(y^{*}(x), x\right) l\right)$ is strictly convex in $x .^{36}$ Now the optimality of $x *$ and the assumption of strict convexity imply

$$
\text { (18) } \begin{aligned}
\frac{d T\left(x, y^{*}(x)\right)}{d x} & =0 \text { at } x^{*} \\
& >0 \text { for } x>x^{*} .
\end{aligned}
$$

But and $^{37}$

$$
\text { (19) } T\left(x, y^{*}(x)\right)-(x+p(x) q(y *(x), x) \ell)=p(x) y^{*}(x) \text {, }
$$

$$
\text { (20) } \frac{d\left(p(x) y^{*}(x)\right)}{d x}<0 \text {. }
$$

Thus, the derivative of $x+p(x) q\left(y^{*}(x), x\right) l$ exceeds that of $T\left(x, y^{*}(x)\right)$, and this fact and (18) give the result. Q.E.D.

Proposition 12. Under the negligence rule without the defense of contributory negligence, an optimal result will not be achieved; the victim will take too little care, although if a dangerous condition arises, the injurer will act optimally given the victim's behavior.

Proof: We wish to show that $x<x^{*}$ and $y=y^{*}(x)$. Let us first note that $y(x)=y^{*}(x)$ for all $x$. This can be proved in exactly the way the same fact was shown for $x \geqq x^{*}$ in the proof to the previous proposition. 
Since the injurer will always act non-negligently, the victim will bear his losses and thus will choose $\mathrm{x}$ to minimize $x+p(x) q\left(y^{*}(x), x\right) \ell$. But it was shown at the end of the last proof that this expression has a positive derivative for $x \geqq x^{*}$, so that it must be minimized at an $x$ less than $\mathrm{X} *$ Q.E.D.

Proposition 13. Under the comparative negligence rule, an optimal result may not be achieved.

(This is obvious from the discrete version of the model. )

Proposition 14. Under strict liability with the defense of contributory negligence, an optimal outcome will be achieved; both the victim and the injurer will choose optimal levels of care.

Proof. We wish to show that $x=x^{*}$ and $y=y^{*}$. In regard first to $y(x)$, it is clear that if $x<x^{*}$, then $y(x)=0$. On the other hand, if $x \geqq x^{*}$, then since the injurer will be liable, his problem is to minimize $y+q(y, x) l$. Hence $y(x)=y^{*}(x)$ for $x \geqq x^{*}$.

The victim's problem is accordingly

(21) $\min \left(\min _{x<x^{*}} x+p(x) q(0, x) \ell, \min _{x \geqq x^{*}} x\right)$,

and from (17), it is clear that the solution to this problem is $x^{*}$ Q.E.D. 
B. Case where injurers act first

In this case, $q(y)$ and $p(x, y)$ will be defined analocously to $p(x)$ and $q(y, x)$. Moreover, expected total costs will now be

(22) $\mathrm{T}(\mathrm{x}, \mathrm{y})=\mathrm{y}+\mathrm{q}(\mathrm{y})(\mathrm{x}+\mathrm{p}(\mathrm{x}, \mathrm{y}) \ell)$;

and $x^{*}(y)$ will be the optimal $x$ given $y$; it will minimize (23) $x+p(x, y) \ell$.

Let us now briefly reexamine the functioning of the liability rules.

Proposition 15. Under the negligence rule with the defense of contributory negligence, an optimal outcome may not be achieved; the injurer may take too little care, although the victim will act optimally given the injurer's behavior. Proof. We wish to show that $y<y^{*}$ is possible and that $x=x^{*}(y)$. The latter is true since by now familiar logic, $x(y)=x^{*}(y)$. Hence, the injurer's problem is (24) $\left.\min _{y^{<} y^{*}} y+q(y) p\left(x^{*}(y), y\right) \ell, \min _{y \geqq y^{*}} y\right)$,

and it is clear that the solution to this problem might be $y$ $<y^{*}$. (This would be so if $p\left(x^{*}(y), y\right)$ were sufficiently low.) Otherwise, of course, the solution is $y^{*}$, in which case an optimal outcome results. Q.E.D.

Proposition 16. Under the negligence rule without the defense of contributory negligence, an optimal outcome will be achieved; both the injurer and the victim will choose optimal levels of care. 
Proof: We wish to show that $y=y^{*}$ and $x=x^{*}$. Now if $y<y^{*}$, then $x(y)=0$; and if $y \geqq y^{*}$, the victim will choose $x$ to minimize $x+p(x, y) \ell$, so that $x(y)=x^{*}(y)$. Hence, the injurer's problem is

(25) $\left.\underset{y^{<} y^{*}}{\min (\min y}+q(y) p(0, y) l, \min _{y \geqq y^{*}} y^{*}\right)$.

By an argument analogous to that used in respect to the problem (21), the solution to (25) is seen to be $y^{*}$. Thus, the victim will choose $x^{*}\left(y^{*}\right)=x^{*}$. Q.E.D.

Proposition 17. Under the comparative negligence rule, an optimal outcome may not be achieved.

(As before, this is obvious from the discrete version of the model.)

Proposition 18. Under strict liability with the defense of contributory negligence, an optimal outcome will not be achieved; the injurer will take too little care, although the victim will act optimally given the injurer's behavior. Proof. We wish to show that $y<y^{*}$ and $x=x *(y)$. The latter is true since by familiar logic, $x(y)=x^{*}(y)$. Hence the injurer's problem is

(26) $\min _{y} y+q(y) p(x *(y), y) \ell$

But the derivative of this expression exceeds that of $T\left(x^{*}(y), y\right)$ by the argument used in respect to (19) and (20). Thus, 
assuming $T\left(x^{*}(y), y\right)$ to be strictly convex in $y$, the $y$ that solves (26) must be less than $Y^{*}$ Q.E.D.

We omit discussion of the extension of the model in the continuous version. 


\section{Footnotes}

Professor of Law and Economics, Harvard Law School. I wish to thank Lucian Bebchuk, Mark Klamer, William Landes, A. Mitchell Polinsky, Richard Posner, David Rosenberg, Hal Scott, and Donald Wittman for comments and the National Science Foundation (Grant No. SES-8014208) for financial support.

1. Attention will be limited to the issue of accident avoidance--in particular, no consideration will be given to sharing of risk or to notions of fairness--and conclusions reached about the comparison of liability rules should be interpreted accordingly.

2. The words "victim" and "injurer" will be used in place of the more cumbersome "potential victim" and "potential injurer" hereafter.

3. 10 M. \& W. $546(1842)$.

4. 66 ont. L. R. 618 (App. Div, 1931).

5. In cases involving "last clear chance," it is frequently true that the victim acted first; consider Tuff v. Warman, 5 C.B. (N.S.) 573 (1858), involving a collision of ships, where defendant vessel saw but still ran down plaintiff vessel, which failed to post a lookout; Radley v. London \& Northwestern Railway, 1 App. Cas. 754 (1876), where plaintiff colliery placed one coalcarrying container on top of another on defendant railroad's flat-bed car and where defendant's locomotive engineer, noticing resistance when attempting to pass 
under plaintiff's bridge, failed to investigate and increased his power, doing damage to the bridge; Clark v. Boston \& Maine R.R., 87 N.H. 434, 182 A. 175 (1935), where plaintiff standing on a railway crossing was struck by defendant's train coming from a direction in which he was not looking; Wall v. King, 280 Mass. 577, 182 N.E. 855 (1932), where plaintiff driver attempted to pass in the middle lane of a three lane road when it was difficult for him to then pull back to the right and where defendant coming in the opposite direction thereafter also entered the middle lane despite plaintiff's sounding his horn and collided with plaintiff.

6. In some situations involving last clear chance, and in many involving "assumption of risk," the injurer acted first; suppose that defendant failed to clear ice from his sidewalk and plaintiff, observing the condition of the sidewalk, nevertheless proceeded to walk on it, fell, and suffered injury; that defendant failed to keep his stone wall in good repair and plaintiff still chose to park his car by the wall, from which several stones were dislodged, fell, and damaged the car.

7. The only other articles of which I am aware which consider sequential situations using the approach of micro-economics are Donald Wittman, Optimal Pricing of Sequential Inputs: Last Clear Chance, Mitigation of Damages, and Related Doctrines in the Law, $10 \mathrm{~J}$. Legal Stud. 65 (1981) and 
(in a section) William M. Landes and Richard A. Posner, The Positive Economic Theory of Tort Law, 15 Georgia L. Rev. 851 (1981), at 889-891. Reference to these two articles, to which the reader is encouraged to turn, will be made below (see notes $16,20,24,27$ ). These articles, however, do not contain the principle results shown here (as illustrated by the next two paragraphs on Davies and as precisely stated in the Propositions), do not examine situations where the injurer acts first and the victim second, and do not formally analyze a general model where parties act sequentially. (But see note 27 infra, on Wittman, and see also William M. Landes and Richard A. Posner, Joint and Multiple Tortfeasors, 9 J. Legal stud. 517 (1980), at 543-547, which discusses and formally analyzes a particular (and complicated) type of sequential situation where an injurer acts first, harms a victim, and then another injurer harms the victim.)

8. Herein lies the analytically distinguishing feature of the sequential context. In the simultaneous context, by contrast, each type of party takes as given the actions of the other; each victim assumes that his own action will not affect the actions of injurers, and conversely. See also notes 17 and 28 infra on the difference between the sequential and the simultaneous contexts. 
9. In Davies the court said that were Mann not bound to take care, "a man might justify the driving over goods left on a public highway, or even over a man lying asleep there, or the purposely running against a carriage going on the wrong side of the road."

10. This is a point of emphasis in wittman note 7 supra, it is well recognized in Landes and Posner note 7 supra, and it is the implication of remarks in William L. Prosser, Comparative Negligence, 51 Mich.L.Rev. 465 (1958), at 468 .

11. There is also a brief Appendix analyzing formally a version of the model in which care is assumed to be continuously variable rather than (as in the body of the article) discrete.

12. The cost of care and possible accident losses are assumed to be monetary or to have monetary equivalents.

13. If for example the likelihood of a loss of 1000 is .10, then expected losses are 100. The assumption that parties evaluate uncertain amounts in terms of expected values (the technical assumption of risk neutrality) is made for simplicity; it will be clear that nothing of substance will turn on the assumption.

14. This assumption seems the reasonable one to make even though there will often be a measure of uncertainty in the injurer's mind about the negligence of the victim. (Could a party like Mann have wondered whether a party like Davies had been forced to leave his donkey fettered on the road owing to some emergency?) 
15. The reduction to zero of the probability of an accident accomplished by the injurer's exercise of care is an aspect of the example that will simplify calculations and explanations of results but is not necessary to the results; see section III.

16. This aspect of the example should be thought typical if one believes that it will generally be true that both the victim and the injurer ought to take some degree of care. However, for an alternative viewpoint, see Landes and Posner, note 7 supra. They suggest that in many situations of interest, it is optimal for the injurer alone to take care.

17. In the simultaneous context, however, the negligence rule will lead to an optimal outcome when there is no defense of contributory negligence (as it will if the defense is allowed). See note 28 infra.

18. In the general case of the model studied in the next section, an optimal outcome might occur under this rule if the probability of an accident is not reduced to zero by the injurer's taking care. See Proposition 2. In the version of the model with care continuously variable, however, an optimal outcome would never occur; the victim will always take too little care. See Proposition 12 of the Appendix. (Comments similar to this will apply to other results of this section where a party fails to take care, but we will not bother to make them.) 
19. In the general case, it is not that the victim will have no incentive to take care--he may after all suffer a loss despite the injurer's taking due care. Rather, it is that he will have an inadequate incentive to take care.

20. This observation leads wittman, note 7 supra, to examine a family of liability rules according to some of which the victim would pay the injurer his cost of care--thereby apparently giving the victim an appropriate incentive to reduce the risk of dangerous conditions.

21. Suppose that under a comparative negligence rule the injurer would be liable for half the victim's losses if both failed to take care. Then if a dangerous condition arose and the victim did not take care, the injurer would prefer to spend 200 on care than to fail to take care and bear an expected liability of $.50 \times 500=250$. Knowing this, the victim would decide not to take care.

On the other hand, it is also possible that the injurer would decide against taking care if the victim did not and that an optimal outcome would result. This would be the case, for instance, if the injurer would be liable for only one fifth the victim's losses if both did not take care, for then the injurer's expected liability if he and the victim failed to take care would be only .50 × $200=100$. Hence, if the victim does not take care, his expected losses will be $.20 \mathrm{x}$ $.50 \times 800=80$; and if he takes care, his only costs 
will be his cost of care of 10, as the injurer will then be induced to take care if a dangerous condition arises. Thus, both the victim and the injurer will be led to take care.

22. In the numerical example, the injurer will not take care if a dangerous condition arises and the victim did not take care. But the injurer will take care if the victim did take care; for in that event, the injurer would be liable and would prefer to spend 200 on care than to bear expected liability of $.5 \times 1000=500$. Consequently, if the victim does not take care, his expected losses will be $.20 \times .50 \times 1000=100$; and if he does take care at a cost of 10, he will not bear any losses. Thus, the victim will take care, and so then will the injurer.

23. In the example, if a dangerous condition arises, the victim will always spend 200 on care to avoid an expected loss of 500 . Hence the injurer will have no reason to take care.

24. Thus, the modification might be seen as rationalizing such doctrines as last clear chance. However, Landes and Posner notes 7 and 16, supra, suggest a different rationalization of last clear chance: that it is. employed to defeat a defense of contributory negligence precisely when such a defense would have been inappropriate $a b$ initio--when it would not have been optimal for the victim to have taken any care to avoid creating 
a dangerous condition on account of the ease with which potential injurers could subsegrently prevent accidents.

25. More generally, let $\propto$ be the probability that victims will ignore the risk in the example. Then it will be desirable not to apply the defense of contributory negligence when $\propto 100+(1-\propto) 30>40$, which is to say, when $\propto>1 / 7$. See section III.

26. See (11) of section III for a general formula showing how the chance that a victim or that an injurer would be inevitably negligent will determine the desirability of use of the defense of contributory negligence.

27. This section presents the first formal analysis of the usual rules of liability in the sequential context. (Although wittman, note 7 supra, contains formal analysis of the usual liability rules in the simultaneous context, the only rule that wittman formally analyzes in the sequential context (at 69-71) is a special one (but with interesting and desirable properties) that he calls "marginal cost liability.")

28. In the simultaneous context, this rule can be shown to lead to an optimal outcome. The reason, in essence, is that the victim and the injurer are envisioned each to take care with probability one; thus the victim's level of care does not affect the probability that injurers will take care. By contrast, in the sequential context, the victim's level of care does of course affect whether the injurer will take care, and the victim does not take this into account under the negligence rule without 
the defense of contributory negligence. (Similar remarks explain why comparative negligence leads to an optimal outcome in the simultaneous context but may not in the sequential context.)

29. See for example John P. Brown, Toward an Economic Theory of Liability, 2 J. Legal Stud. 323 (1973); Peter A. Diamond, Single Activity Accidents, $3 \mathrm{~J}$. Legal stud. 107 (1974); and Steven Shavell, strict Liability versus Negligence, 9 J. Legal stud. 1 (1980).

30. This is primarily because the behavior of the second party may depend on the particular level of care exercised by the first party.

31. Although $\ell$ is taken to be fixed, the results to be shown do not depend on this assumption; and the proofs would remain virtually the same were the loss instead variable, determined by a probability distribution (dependent on $\mathrm{x}$ and $\mathrm{y}$ ).

32. Here and occasionally elsewhere, functions or their derivatives are for convenience written without their arguments.

33. The interpretation of $q_{x y} \geqq 0$ is that if the victim increases his level of care, then, if a dangerous condition arises, the effect of an increase in the injurer's care on the likelihood of loss is unchanged or reduced. This corresponds to the notion that the nature of the dangerous condition (as opposed to its probability) is either unaffected by the victim's care or, if affected, becomes less serious. 
34. It will be assumed that the minimization problems of the injurer and of the victim have unique solutinns.

35. The proof of this result will be seen to be different from and more complicated than the proof of the same result in the simultaneous context; for the latter, see John P. Brown, note 29 supra.

36. I know of no simple assumption about $T(x, y)$ that guarantees convexity.

37. To establish (20), note that $d\left(p(x) y^{*}(x)\right) / d x=p^{\prime}(x) y^{*}(x)+$ $p(x) y^{*}(x)$ and that $p^{\prime}(x) y^{*}(x)$ is negative. Thus, we need only show that $y^{* \prime}(x) \leqq 0$. But $y^{*}(x)$ is implicitly determined by the first-order condition from (14), namely $1+q_{y}(y *(x), x) \ell=0$. Differentiating this with respect to $x$ we get $y^{* \prime}(x)=-q_{y x}\left(y^{*}(x), x\right) / q_{y y}\left(y^{*}(x), x\right) \leqq$ 0 . 